\title{
¿Es necesaria la creación de una ley de libre competencia?
}

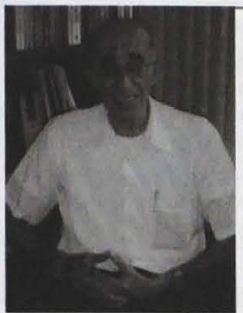

Javier Iblsate, UCA
"Libre mercado, libre comercio, libre competencia" resultan ser, por desgracia, semiutoplas. Cuando el Premio Nobel de Economia Joseph Stiglizı dice que: "el libre comercio en poco o en nada ha beneficiado a los palses pobres y que la teorfa del libre comercio es un fraude intelectual”, ya está resumiendo lo que han demostrado las cumbres de la OMC de Seattle, Doha y Cancún, tal como aparece en los artículos antes citados.

Cuando nuestra Asamblea Legislativa promete publicar "la ley de libre competencia" se contradice con leyes y decretos antes aprobados. Nuestro Gobierno está a favor de la "privatizaciones", siendo así que privarizaciones pueden darse en Europa, Estados Unidos o Japón. En nuestros paises las privatizaciones son "desnacionalizaciones", que generan poderes superiores al mismo Estado. Cuando se privarizóANTEL lo que se creo fue una cesión de un activo nacional a dos transnacionales Telefónica y Telecom, cuya cifra de ventas anuales supera unas diez veces nuestro PIB. Merece la pena leerse a este propósito la conferencia de Frank Hinkelammert: "El socavamiento de los derechos humanos en la globalización actual: la crisis del poder de las burocracias privadas". (Realidad No. 87; mayo-junio 2002) Airticulo interesante porque, entre otras cosas, muestra que "quienes privatizan son los Estados y al privatizar crean poderes superiores a si mismos, convirtiéndose en apéndices de dichos poderes”. Con este proceso de privatizaciones ¡cómo se puede erigir una ley de libre comperencia?

Lo oscuro de los TLCs con USA no es simplemente la poca transparencia de estos tratados (todavia USA anda modificando el tratado final, del cual hay tres ejemplares distintos en la Asamblea Legislativa), qué nos permitirán exportar y qué otras no; lo más temible de estos tratados son los "temas de Singapur": las "inversiones", que es una actualización de Acuerdo Multilateral de Inversiones (AMI) o concesión de igualdad de trato a inversiones extranjeras que a las nacionales, la privatización de servicios públicos (caso telecomunicaciones en Costa Rica), los derechos de propiedad intelectual, la apertura plena de todos los mercados, junto con las masivas subvenciones a sus productos agrícolas, más las ventajas de los productos transgénicos. Este tema aparece en el comentario citado: "Un ALCA a dos velocidades". (ECA, enerofebrero 2004). Por desgracia la globalización hace dificil la libre competencia.

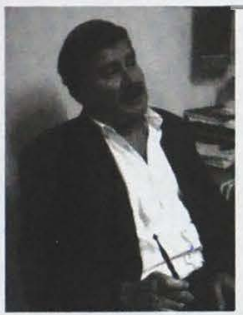

Roberto Rublo,

FUNDE



Héctor Dada Hirezl,

Dipurado COU
Muy necesaria, y me extrańa por que se supone que los que han dirigido económicamente este país en los últimos ańos han sido unos mercaderes de libre comercio y de la comperencia, pero cuando uno aterriza a lo concreto, se dice no toquemos esto porque no es monopolio o el monopolio es bueno. En esa discusión las iniciativas de ley sobre libre comperencia y no han prosperado. Esperamos que con este nuevogobierno se apruebe una ley de libre competencia, eso es básico para evitar las distorsiones del mercado y para que la comperitividad se base no en el control del mercado sino en la productividad. 


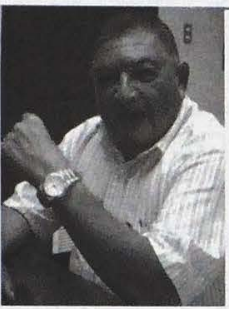

Jorge Barraza lbarra, UTEC

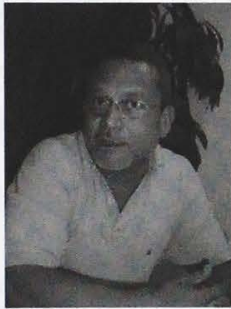

Carlos Briones, FLACSO
En un país como el nuestro, en el que permanentemente se ensalzan las virtudes del libre mercado, parecería que es un contrasentido tener que implementar instrumentos jurídicos para regular las relaciones en el mercado, cuando todos, especialmente los empresarios, no dudan que hay que proteger y defender los principios del sistema. Una ley de libre competencia significa que existen violadores a la libertad, equidad y transparencia del sistema, en abierta contradicción al modelo que se defiende. Pero, esto no debe sorprender, pues generalmente existe una tendencia hacia el engrandecimiento de las empresas, a costa de los más débiles, utilizando todos los medios -lícitos e ilícitos- de que se disponen. Históricamente existen varios ejemplos sobre regulaciones en el mercado, en los Estados Unidos, la Ley Sherman sobre los monopolios en 1911, la Ley Antimonopolios de Clayron en 1914, que prohibla tipos específicos de discriminación de precios y fusiones mediante adquisición de acciones entre empresas de la competencia, y las leyes anticárteles, para prohibir los convenios contractuales para compartir mercados o fijar precios.

Pareciera ser, si se atienden las quejas de los pequeños y medianos empresarios, así como también, de los manifiestos signos de insatisfacción de los consumidores, que una Ley reguladora de la libre competencia es muy necesaria en nuestro país. Pero siempre que sirva, pues estamos acostumbrados a leyes reguladoras, pomposas instituciones supervisoras, sistemas para llevar equidad al mercado, que no funcionan. Otro adefesio demagógico para ef ectos del discurso polírico, no es necesario.

La Ley de libre competencia puede influir en la competitividad, porque se puede tener una regulación pero si se cuenta con una mano de obra poco educada y calificada, malas condiciones de inf raestructura comunicacional, podemos tener baja competitividad y baja productividad.

Pero la ley de libre competencia es fundamental para varias cosas, primero para que se desarrolle más fluidamente ciertos proceso en los cuales al no haber monopolios o cuasimonopolios en ciertas actividades puedan entrar diferentes agentes o dif erentes productores y finalmente el que produce más y a más bajos costos será el que se irá imponiendo su producto en el mercado y no porque haya alguien que tenga el poder de vetar o imposibilitar que otra persona entre.

La Ley de libre competencia en mi opinión, ayuda a fomentar el autodescubrimiento nacional de los agentes económicos más eficientes. La Ley de libre competencia tiende a equilibrar el poder de los productos con el poder del consumidor, que eso es necesario, que es fundamental para el bienestar de la población.

Asimismo, una ley de libre competencia tiende a legitimar el funcionamiento del mercado, porque la mejor manera de venderle la idea a las personas de que el mercado es bueno, de que la privatización de algunos servicios pueden ayudar a que se produzcan de manera más eficiente, es la seguridad que se le ofrece de que si emprende una actividad económica, podrá mantenerse en el mercado si es lo suficientemente eficiente y competitivo.



Rafael Rodríguez Loucel, UTEC
Como literalmente lo manifestó La Universidad Tecnológica en un documento titulado "Propuesta al Señor Presidente 2004 2009" el funcionamiento armónico del sistema económico debe garantizar el acceso de todos los ciudadanos al disfrute de los bienes y servicios del Producto Social, evitando las distorsiones malsanas que inclinan preferencias hacia grupos privilegiados de cualquier clase y signo. La economía tiene como beneficiario, último y legfrimo, al ciudadano que diariamente se enfrenta al reto de crear bienes y generar riqueza. De inmediato, con mucha urgencia, es indispensable que el Estado asuma su papel de árbitro en la transferencia de bienes y riquezas, con equidad, con justicia social, premiando todos los que participan en dichos esfuerzos. Se necesita una iniciativa de Ley de Libre Competencia para regular positivamente el esfiuerzo de los empresarios, el precio de los bienes, el uso de los insumos y el acceso a los factores de la producción sin discriminaciones, especialmente artificiosas, que dafian la actividad productiva. Es necesario acentuar que el Estado debe propender hacia un espiritu de concertación, dando el debido espacio, sin asumir el papel de juez, a la expresión de los sectores involucrados. 